\title{
The impact of altitude, latitude, and endurance duration on the Design of a High Altitude, Solar Powered Unmanned Aerial Vehicle
}

\author{
Ahmad Alsahlani \\ School of Computing, Science \& Engineering \\ University of Salford \\ United Kingdom \\ ahmad.alsahlani@gmail.com
}

\author{
Thurai Rahulan \\ School of Computing, Science \& Engineering \\ University of Salford \\ United Kingdom \\ t.rahulan@salford.ac.uk
}

\begin{abstract}
In this paper, a previously developed conceptual design tool has been used to study the impact of the latitude, altitude, and the flight duration on the weight estimation and the main characteristics of a high altitude, long endurance and solar powered unmanned aerial vehicle. The available solar energy during the daylight hours has been calculated at given locations and altitudes for specific periods to be used in the pre-conceptual design stage. The pre-conceptual design methodology is based on an analytical and continuous method, which consists of establishing the relationships between all the components with analytical functions using the component characteristics. This design approach can directly provide a unique and optimal design. This study is conducted for a solar aircraft designed for a surveillance mission over Iraq. It is concluded that increasing the operational altitude can lead to a heavier aircraft in spite of the high levels of the available solar energy that can be absorbed. Hence, at high altitude, the surface area required for solar power generation is less than that needed to obtain adequate lift. Increasing the maximum solar irradiance during the daylight hours can lead to further lowering of the aircraft weight. Moreover, an increase in the daylight hours can be beneficial if the charging and discharging losses of the fuel cells are considered.
\end{abstract}

Keywords-solar powered aircraft; high altitude; long endurance; UAV design

\section{INTRODUCTION}

Solar powered high altitude long endurance unmanned air vehicles can provide many benefits in military and civilian applications. Sustained flight at high altitudes involves a range of challenges such as low air density which can cause problems in generating sufficient lift and thrust. Aircraft speed can be adjusted but the limitation associated with the available power to the propulsion system is the primary challenge if the required endurance needs to be prolonged. Hence, the design trend is to increase the wing area as well as the lift coefficient. The wing area is also important to accommodate solar cells panels required to absorb the radiated energy necessary to operate aircraft for a specified period of time. Therefore, energy and mass balance are taken as a starting point for the design of solar-powered aircraft. This balance is required to deal with this multi-disciplinary engineering field. Two different approaches can be adopted to achieve the conceptual design [1]. The first one is based on a pure estimation for the first set of components (motors, solar cell panels, fuel cell or batteries, and avionic system). From the weight of these components, one can estimate the total weight and required power. The last power estimation is then compared with the previous estimate, and the process is performed iteratively until a converged solution is found [1,2]. The second approach is based on using all the relationships between all the aircraft components with analytical functions using the component characteristics, but this approach must be supported by recently developed analytical equations updated with statistical data extracted from existing relevant aircraft. In a companion paper Alsahlani \& Rahulan developed an analytical pre-conceptual design approach to design a high altitude long endurance solar powered aircraft for a given mission which employs the aerodynamic performance, payload, altitude, latitude and endurance period. This is the design tool that will be used in this study.

The flight altitude, location, and the endurance period are the primary focus of study. The available solar energy depends on the geographic location, altitude, time of the day and the day of the year. Several solar models are available from previous studies to estimate the solar power at given time, altitude, and location [3].

In this paper, a set of mission requirements will be assumed in order to investigate how they will affect the gross weight of the aircraft and its main characteristics. The first part of this research is to calculate the available solar power at given latitude and altitude during specific periods of time. In the second part, a recently developed pre-conceptual design by the authors will be used to estimate the aircraft weight as well as its main characteristics.

\section{Preconceptual Design Model}

An analytical design tool has been used to size the aircraft components for a given mission. This tool was developed and detailed in companion papers [2, 4] and only the main equations will be mentioned in this paper. The methodology is similar to that adopted by Noth $[1,5]$, but it is tailored for designing solar powered high altitude long endurance aircraft. This tool can directly provide, for a specific set of mission requirements, the optimal design which includes weight and power of the aircraft components in addition to its main characteristics such as the 
planform area, the aspect ratio, and the wing span. Basically, the lift force generated by the aircraft at the appropriate flight level must be equal to its weight; likewise, the drag must be equal to the thrust. The required power for level flight $\left(P_{l e v}\right)$ can be calculated by [6-8]:

$$
\begin{gathered}
P_{\text {lev }}=\frac{C_{D}}{C_{L}^{1.5}} \sqrt{\frac{2 A R g^{3}}{\rho}} \frac{m^{1.5}}{b} \\
C_{D}=C_{D o}+\frac{C_{L}^{1.5}}{e \pi A R}
\end{gathered}
$$

where $S$ is the planform wing area, $\rho$ the air density, AR the aspect ratio, e is the span efficiency factor, $\mathrm{b}$ is the span, $C_{L}$ is the design reference lift coefficient of the aircraft, $m$ is the total mass, and $C_{D o}$ is the zero lift drag coefficient.

The total electric power consumption $\left(P_{\text {elec tot }}\right)$ can be given by:

$$
P_{\text {elec tot }}=\frac{1}{\eta_{t}} P_{\text {lev }}+\frac{1}{\eta_{\text {bec }}}\left(P_{\text {av }}+P_{\text {pld }}\right)
$$

where $\eta_{t}$ is the efficiency represented the power losses in the gearbox, propeller, motors, and the controller. $P_{p l d} \& P_{a v}$ are the required power for given payload and avionics systems respectively. $\eta_{b e c}$ is the voltage converter efficiency.

The consumed power during the daytime $\left(T_{\text {day }}\right)$ must be enough to operate the aircraft over a 24 hour period $\left(T_{\text {day }}+T_{\text {night }}\right)$. The solar energy can be saved using storage schemes such as a fuel cell or batteries. The performance of the power storage capability during the charging and the discharging cycle is not ideal and hence this has to be taken into account by employing the charging and the discharging efficiencies $\eta_{\text {chrg }}$ and $\eta_{\text {dchrg }}$. The total energy required ( $E_{\text {elec tot }}$ ) over a 24 -hour period for level flight can be evaluated by:

$$
E_{\text {elec tot }}=P_{\text {elec tot }}\left(T_{\text {day }}+\frac{T_{\text {night }}}{\eta_{\text {chrg }} \eta_{\text {dchrg }}}\right)
$$

This total electric energy must be equal to the net solar energy consumed by the solar cell panels. The available solar energy $\left(E_{S o l}\right)$ inside the atmosphere depends on the flight altitude, latitude, the number of daylight hours and the time of the year $[9,10]$. The effects of the curvature of the panels and the efficiencies of both the solar cells and the power adapter can be incorporated in the energy equation by $\eta_{c b r}, \eta_{s c}$, and $\eta_{m p p t}$ respectively:

$$
E_{\text {elec tot }}=E_{\text {Sol }} A_{s c} \eta_{c b r} \eta_{s c} \eta_{m p p t}
$$

where $A_{s c}$ is the total solar cell area.

The mass and the power of each aircraft component can be estimated as a constant fraction of either the structural mass or the total mass, or of the total power. These fractions were evaluated statistically from existing solar powered UAV data, which are likely to improve with future technological developments. For more detail the reader is referred to $[2,4]$.

The outcome of the pre-conceptual design tool will be the design space of the aircraft for the given mission requirement such as shown as an example in Fig.1. The optimal design is then selected as the minimum gross weight. The last choice will then lead to the corresponding optimal characteristics of various components. For all the design cases presented in this paper, the aerodynamic performance, the efficiencies of components and the payload requirements are assumed to be constant during the design process as detailed in Table I.

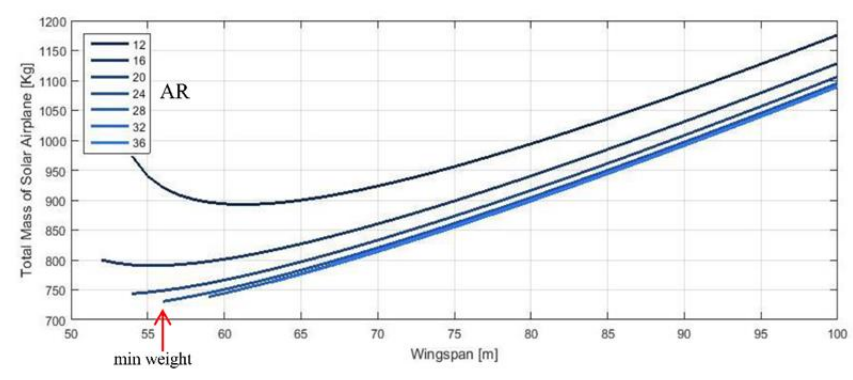

Fig. 1. The design space of sample of the result of the pre-conceptual design tool

TABLE I. THE FIXED MISSION REQUIREMENT

\begin{tabular}{|c|c|c|l|}
\hline Parameter & Value & Units & \multicolumn{1}{|c|}{ Description } \\
\hline $\mathrm{C}_{\mathrm{L}}$ & 0.85 & - & Aircraft lift coefficient \\
\hline $\mathrm{C}_{\mathrm{D} 0}$ & 0.012 & - & Aircraft zero lift drag coefficient \\
\hline $\mathrm{e}$ & 0.95 & - & Oswald's efficiency factor of wing \\
\hline$m_{\text {payload }}$ & 100 & $\mathrm{~kg}$ & Payload mass \\
\hline$P_{\text {payload }}$ & 1250 & $\mathrm{~W}$ & Payload power consumption \\
\hline$\eta_{\text {dchrg }}$ & 0.99 & - & Discharging efficiency \\
\hline$\eta_{\text {chrg }}$ & 0.6 & - & Charging efficiency \\
\hline$\eta_{t}$ & 0.728 & - & Efficiency represents the power losses \\
\hline$\eta_{c b r}$ & 0.9 & - & Curvature of the panel efficiency \\
\hline$\eta_{s c}$ & 0.3 & - & solar cell efficiency \\
\hline$\eta_{m p p t}$ & 0.95 & - & power adapter efficiency \\
\hline
\end{tabular}

\section{Available Solar Radiation At High Altitude}

The emitted radiation from the Sun is nearly constant outside the atmosphere. A useful parameter can be used to measure the solar power outside the atmosphere per unit area normal to the beam direction and per unit time called solar constant $\left(I_{S C}\right)$ and its value is $1367 \mathrm{~W} / \mathrm{m}^{2}$. The local intensity of radiation $\left(I_{0}\right)$ can be determined using the angle $\left(\theta_{z}\right)$ between the direction of the solar beam and the direction perpendicular to the surface of the atmosphere. This angle varies during the day for a given location, which is associated with the latitude and the location of the Earth along its elliptical orbit around the Sun. The solar power available outside the atmosphere per unit area is given by [11]:

$$
I_{0}=I_{S c}\left(1+0.033 \cos \left(n \frac{360}{365}\right)\right) \cos \theta_{z}
$$

where $n$ is the day number, $\theta_{z}$ is the zenith angle which can be calculated using the equation:

$$
\cos \theta_{z}=\cos \varphi \cos \delta \cos \omega+\sin \varphi \sin \delta
$$

where $\varphi, \delta$, and $\omega$ are the latitude angle, Earth declination angle, and hour angle due to Earth rotation respectively. The latter angles can be calculated using the equations:

$$
\begin{gathered}
\delta=23.45 \sin \left(365 \frac{284+n}{365}\right) \\
\omega=\cos ^{-1}(-\tan \varphi \tan \delta)
\end{gathered}
$$

When the solar radiation penetrates the atmosphere, depending on the given altitude and location, a part of the radiation can be scattered towards space and towards the Earth whilst some parts 
are absorbed by the atmosphere gases [12] as shown in Fig.2. The total solar radiation at high altitude can be classified into three principal components; the direct radiation $\left(I_{\text {dir }}\right)$, diffuse radiation $\left(I_{\text {diff }}\right)$, and reflected radiation. At high altitude, due to the relatively cloud-free sky and low humidity, the reflected radiation can be neglected [12]. Therefor the total solar radiation can be given by:

$$
I_{\text {tot }}=I_{\text {dir }}+I_{\text {diff }}
$$

The direct solar radiation can be evaluated using an empirical model as a function of the altitude and the solar elevation angle which is valued for altitudes higher than $10 \mathrm{~km} \mathrm{[3]:}$

$$
\begin{gathered}
I_{d i r}=I_{0} \exp \left\{\frac{c_{s} \exp \left(-\frac{h}{h_{s}}\right)}{\left[\sin \left(\frac{\alpha_{s}+\alpha_{d e p}}{1+\alpha_{d e p} / 90}\right)\right]^{S_{s}+h / h_{b}}}\right\} \\
\alpha_{d e p}=0.57+\cos ^{-1}\left(R_{E} /\left(R_{E}+h\right)\right) \\
\alpha_{s}=\frac{\pi}{2}-\theta_{z}
\end{gathered}
$$

where $\mathrm{h}$ is the altitude in $\mathrm{km}$ and $\alpha_{\text {dep }}$ is the depression angle. All the constants are tabulated in Table II.

The diffuse radiation can be defined as a function of the direct radiation and the altitude:

$$
I_{\text {diff }}=0.08 I_{\text {dir }} \exp \left(-\frac{h}{h_{s}}\right)
$$

The total solar energy can be calculated by integrating (10) for the daytime period:

$$
E_{\text {day }}=\int I_{\text {tot }} d t
$$

TABLE II. CONSTANTS DEFINITIONS OF THE SOLAR RADIATION MODEL

\begin{tabular}{|c|c|l|}
\hline Constant & Value & Definition \\
\hline$c_{S}$ & 0.357 & constant \\
\hline$h_{s}$ & $7 \mathrm{~km}$ & Height constant \\
\hline$h_{b}$ & $40 \mathrm{~km}$ & Height constant \\
\hline$S_{S}$ & 0.678 & constant \\
\hline$R_{E}$ & $6356.8 \mathrm{~km}$ & Earth radius \\
\hline
\end{tabular}

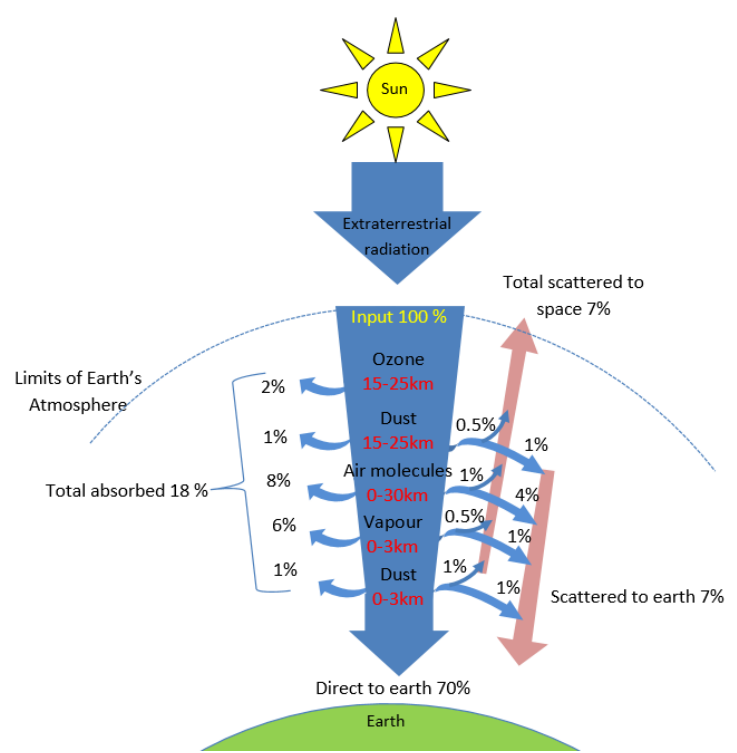

Fig.2. Beam radiation reduction through the atmosphere

\section{AVAILABILITY OF SOLAR ENERGY}

The solar model has been used to calculate the available solar energy for different endurance periods at various altitudes and latitudes. In each case of a flight duration, the minimum available solar energy per day is considered as a reference parameter for the pre-conceptual design process. The study was aimed at designing a high altitude long endurance solar powered aircraft for a surveillance mission over a specific area in Iraq which lies between latitudes $29^{\circ}$ and $38^{\circ} \mathrm{N}$. it had to carry a 100 $\mathrm{kg}$ payload with the system rated at $1250 \mathrm{~W}$. The available solar energy is calculated at different altitudes and latitudes for various times as follows:

\section{A. Design Periods}

Three design durations has been adopted to study how the endurance and the start time of mission can affect the aircraft design. These periods are tabulated in Table III and showed in Fig.3 and Fig.4.

\section{B. Altitude}

The availability of solar energy versus the design altitude has been investigated at a latitude of $32^{\circ}$. Fig.3 illustrates the variation of the solar energy at different altitudes in addition to the daytime hours. It can be seen that the scattering and the absorption of energy is more pronounced at lower altitudes. So the available radiation will be more abundant at higher altitudes.

\section{Latitude}

The available solar energy per day has been calculated using the solar model for an altitude of $17 \mathrm{~km}$ for the given range of latitudes. Fig.4 shows that the available solar energy is high at lower latitude angles except on some days in June and July due to the long daytime hours. The minimum solar energy per day is found for each flight duration as detailed in Table V.

TABLE III. STARTING DATES AND ENDURANCE OF MisSions

\begin{tabular}{|l|l|c|}
\hline \multicolumn{1}{|c|}{ Durations } & \multicolumn{1}{|c|}{ Dates } & Endurances [days] \\
\hline Duration 1 & Whole year & 365 \\
\hline Duration 2 & $1^{\text {st }}$ March $-12^{\text {th }}$ August & 222 \\
\hline Duration 3 & 1 st May -14 th October & 100 \\
\hline
\end{tabular}

TABLE IV. Available Solar ENERgy AND Daytime Hours AT DFFERENT ALTITUDES

\begin{tabular}{|l|c|c|c|c|c|}
\hline Durations & Daytime & \multicolumn{4}{|c|}{ Solar radiation [MJ/m2/day] at altitude } \\
\cline { 3 - 6 } & {$[\mathbf{h}]$} & $\mathbf{1 0} \mathbf{~ k m}$ & $\mathbf{1 5} \mathbf{~ k m}$ & $\mathbf{2 0} \mathbf{~ k m}$ & $\mathbf{2 5} \mathbf{~ k m}$ \\
\hline Duration 1 & 9.985 & 17.83 & 18.45 & 18.76 & 18.91 \\
\hline Duration 2 & 11.392 & 26.58 & 27.54 & 28.02 & 28.26 \\
\hline Duration 3 & 13.254 & 35.63 & 37.19 & 38.00 & 38.41 \\
\hline
\end{tabular}

TABLE V. AVAILABLE SOlar ENERGy AND DAYTIME HOURS AT DFFERENT LATITUDES

\begin{tabular}{|l|c|c|c|c|c|}
\hline \multirow{2}{*}{ Durations } & & \multicolumn{4}{|c|}{ At Latitude $[\mathbf{d e g}]$} \\
\cline { 3 - 6 } & & $\mathbf{3 0}^{\mathbf{0}}$ & $\mathbf{3 2}^{\mathbf{0}}$ & $\mathbf{3 4}^{\mathbf{0}}$ & $\mathbf{3 6}^{\mathbf{0}}$ \\
\hline \multirow{2}{*}{ Duration 1 } & Solar radiation $\left[\mathrm{MJ} / \mathrm{m}^{2} /\right.$ day $]$ & 19.12 & 18.01 & 16.80 & 15.60 \\
\cline { 2 - 6 } & Daytime $[\mathrm{h}]$ & 10.07 & 9.90 & 9.73 & 9.55 \\
\hline \multirow{2}{*}{ Duration 2 } & Solar radiation $\left[\mathrm{MJ} / \mathrm{m}^{2} /\right.$ day $]$ & 28.41 & 27.55 & 26.65 & 25.73 \\
\cline { 2 - 6 } & Daytime $[\mathrm{h}]$ & 11.45 & 11.40 & 11.35 & 11.30 \\
\hline \multirow{2}{*}{ Duration 3 } & Solar radiation $\left[\mathrm{MJ} / \mathrm{m}^{2} / \mathrm{day}\right]$ & 37.62 & 37.54 & 37.41 & 37.24 \\
\cline { 2 - 6 } & Daytime $[\mathrm{h}]$ & 13.20 & 13.30 & 13.41 & 13.52 \\
\hline
\end{tabular}



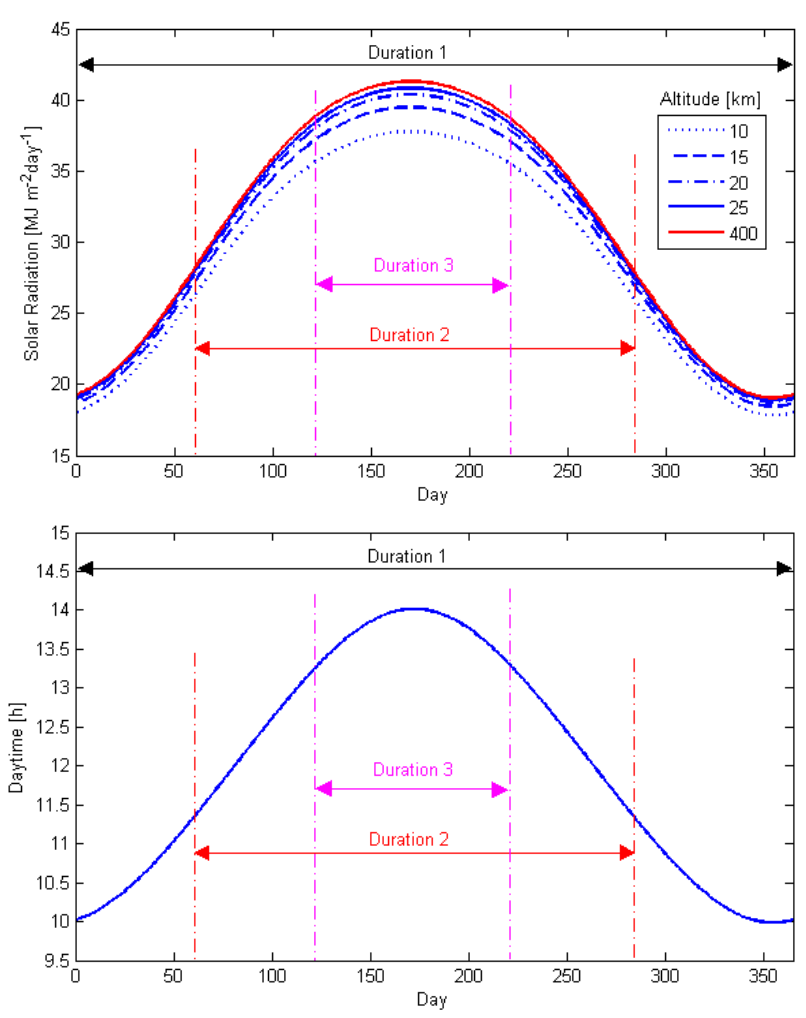

Fig.3. Solar irradiance per unit area and daytime hours versus time for different altitudes at $32.01^{\circ}$ latitude
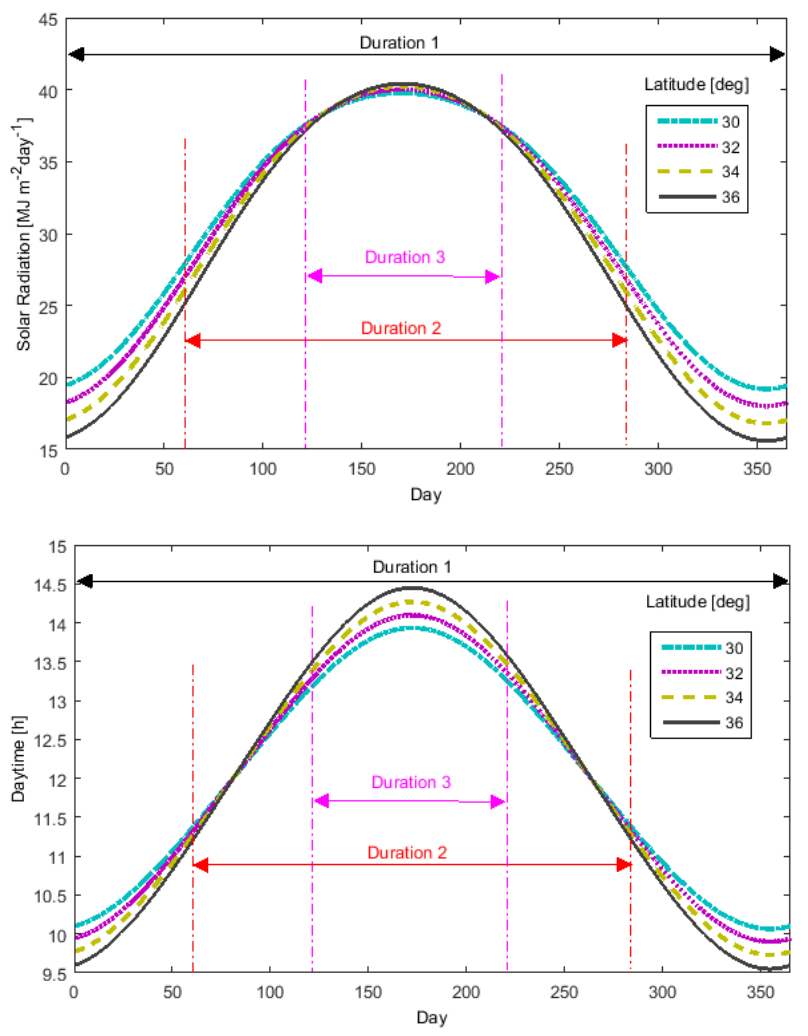

Fig.4. Solar irradiance per unit area and daytime hours versus time for different latitude at $17 \mathrm{~km}$ altitude

\section{Pre-Conceptual Design Results}

The pre-conceptual design tool has been used to study the impacts of altitude, latitude, and endurance duration on the total weight and the main aircraft characteristic such as the aspect ratio and the wingspan. The available energy of each design case has been calculated in the previous section. The fixed mission and aerodynamic performance parameters are tabulated in Table I.

\section{A. Impacts on the Reference Altitude and The Flight Duration}

Fig.5 shows the effects of the design flight altitude on the aircraft weight, the corresponding wingspan, the wing aspect ratio and the ratio of the area of the solar cells divided by the wing area for the three flight durations. The results show that increasing the reference altitude of the design can lead to a heavier aircraft due to a larger wing requirement. This is accompanied by a proportional increase in the wingspan as can be seen in Fig.5.

Since the available solar power in the Durations $2 \& 3$ is increased, the aircraft gross weight and the wingspan are reduced. The aspect ratio of the wing does not seem to be affected at altitudes above $15 \mathrm{~km}$. This is because the wing area needed for the solar cells is less that needed for the aerodynamic performance. The wing aspect ratio and the ratio of solar cell area to wing area are not noticeably affected by the variation in the flight duration.

\section{B. Impacts of the Reference Latitude and Duration}

The effects of the reference latitude of aircraft are shown in Fig.6. The reference altitude is fixed for the design at $17 \mathrm{~km}$. As shown in this study, the gross weight is slightly influenced by changing the design latitude due to the variation in the angle of incidence of solar radiation.

In Duration 3, the influence of the gross weight differs from that for cases Durations $1 \& 2$ in spite of the available solar energy decreasing with increasing latitude. However, the daytime period increases for Duration 3 as shown in Table $\mathrm{V}$ and Fig.3. This difference of influence is because that the solar energy required to operate the aircraft during the night time, is stored in fuel cells which in turn suffers charging and discharging power losses of about $40 \%$ (see Table I and (4)). Therefore, the daytime period is also a noticeable factor besides the available solar energy as it can influence achievement of the design aims. The span of the wing is affected in the same manner as the gross weight. The results also show that the wing aspect ratio is not affected by the variation in the latitude. The ratio of the area covered by the solar cells to the wing area is slightly increased with increasing latitude for each duration case. Also, it is affected by the periods due to the effects of solar energy and daytime flight. 

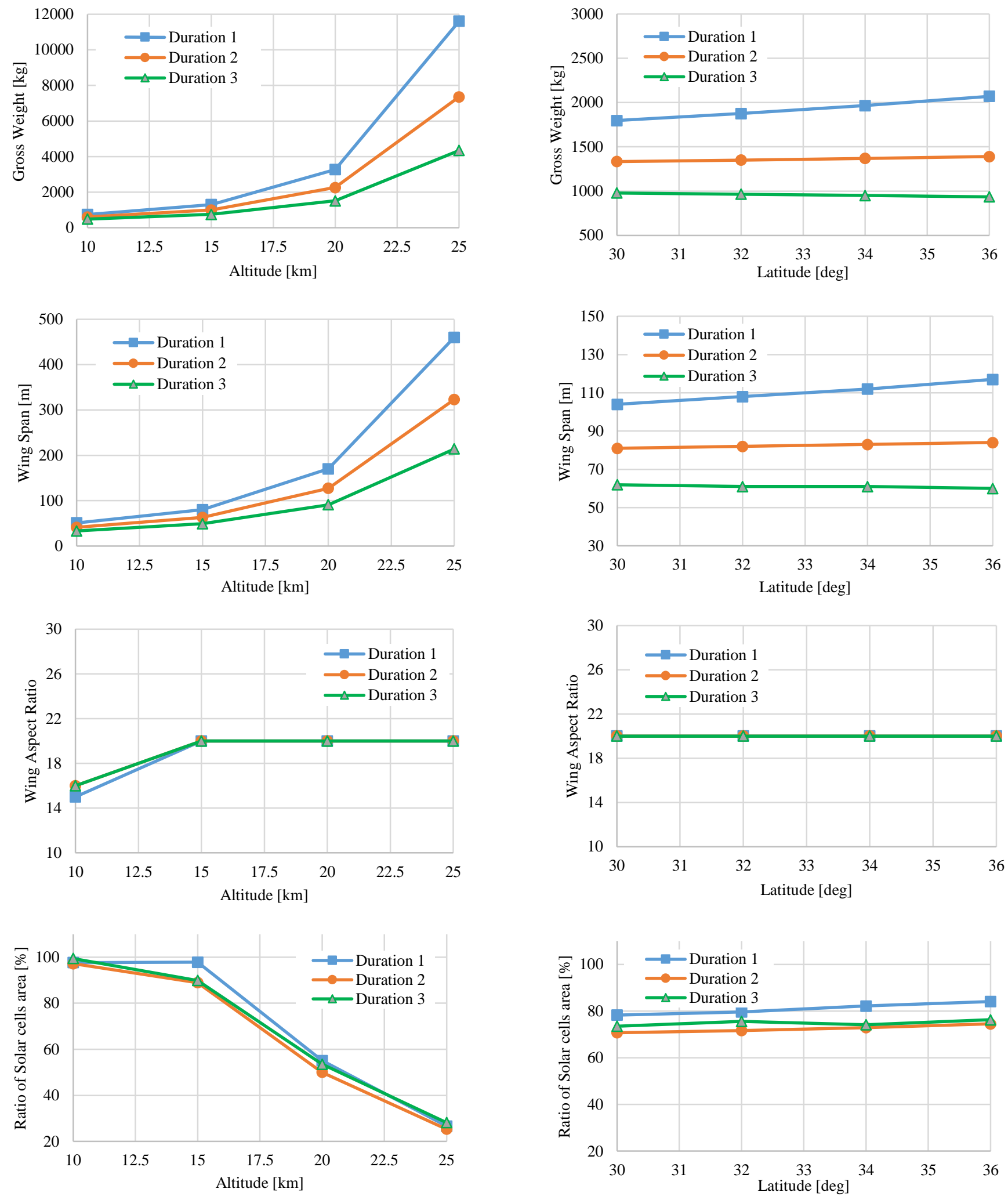

Fig.5. Effect of the flight altitudes on gross weight, corresponding wingspan, wing aspect ratio and the ratio of solar cells area for different flight durations. At latitude $=31.01^{0}$.

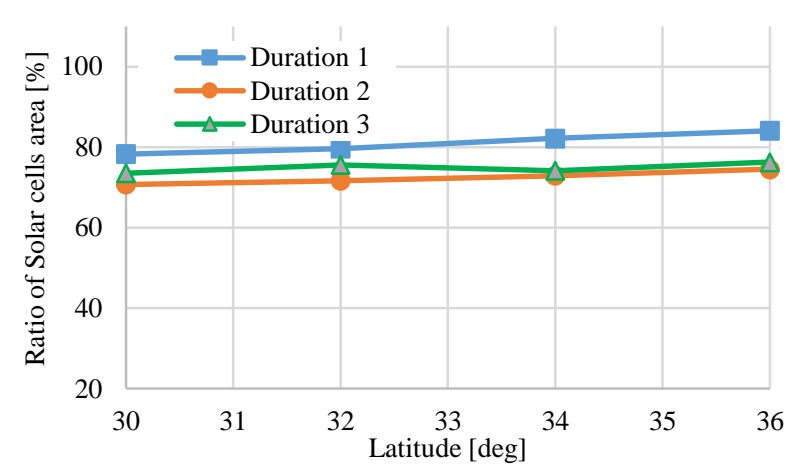

Fig.6. Effect of the flight latitudes on gross weight, corresponding wingspan, wing aspect ratio and the ratio of solar cells area for different flight durations. At altitude $=17 \mathrm{~km}$. 


\section{CONCLUSION}

This research was conducted to study the effects of the operational latitude and the altitude for different flight durations on design of high altitude long endurance solar powered aircraft. It is concluded that for all design cases considered, increasing the operational altitude can lead to a heavier aircraft, in spite of the availability of larger amounts of solar energy at higher altitudes. For the same reason, at high altitudes, the required wing area for solar cells is less than that needed for lift generation. Increasing the maximum solar irradiance and the daylight hours, which highly depend on the geographic location, flight duration and altitude, can lead to lowering of the aircraft weight. The start and finish date of a mission is closely related to the number of daylight hours and the available solar energy. Increas in the daylight hours will also reduce the fuel cell charging and the discharging losses.

\section{ACKNOWLEDGMENT}

The authors would like to thank the higher committee of education of Iraq (HCED-IRAQ) for supporting this study at the University of Salford.

\section{REFERENCES}

1. Noth, A., Design of Solar Powered Airplanes for Continuous Flight. 2008, PhD thesis, ETH ZÜRICH.

2. Alsahlani, A. and T. Rahulan, Weight Estimation of a Conceptual Wing for a High Altitude, Solar Powered Unmanned Aerial Vehicle, in 5th Aircraft Structural Design Conference 2016, The Royal Aeronautical Society: Manchester / UK.

3. Min Chang, et al., A General Design Methodology for Year-Round Solar-Powered Stratospheric UAVs from Low to Middle Latitudes. 2014.

4. Alsahlani, A., L.J. Johnston, and P.A. Atcliffe, Design of a High Altitude Long Endurance Flying-wing Solar-Powered Unmanned Air Vehicle, in 6TH European Conference for Aeronautics and Space Sciences (EUCASS2015). 2015, EUCASS: Krakow, Poland.

5. Noth, A., R. Siegwart, and W. Engel, Design of solar powered airplanes for continuous flight. 2008.

6. Manuel, H., Design, Construction and Test of the Propulsion System of a Solar UAV Thesis, in Aerospace Engineering. 2013, Tecnico Lisboa.

7. Gao, X.-Z., et al., Energy management strategy for solar-powered high-altitude long-endurance aircraft. Energy Conversion and Management, 2013. 70: p. 20-30.

8. Cestino, E., Design of solar high altitude long endurance aircraft for multi payload \& operations. Aerospace Science \& Technology, 2006. 10(6): p. 541-550.

9. Zhu, X., et al., How High Can Solar-Powered Airplanes Fly. Journal of Aircraft, 2014. 51(No. 5, September-October 2014): p. 1653 1658.

10. P. Guarino, et al., Design of Solar Powered Ultra-light Aircrafts Realization of a Model and its Validation. International Journal of Energy, 2014. V8.

11. Duffie, J.A. and W.A. Beckman, Solar engineering of thermal processes. Vol. 3. 2013: Wiley New York.

12. Rizzo, E. and A. Frediani, A model for solar powered aircraft preliminary design. The Aeronautical Journal, 2008(February ): p. 57-87. 